\title{
Optimization of Cucumber Doubled Haploid Line Production Using In Vitro Rescue of In Vivo Induced Parthenogenic Embryos
}

\author{
Elisabet Claveria, Jordi Garcia-Mas, and Ramon Dolcet-Sanjuan ${ }^{1}$ \\ Departament de Genètica Vegetal, Institut de Recerca i Tecnologia Agroalimentàries (IRTA) Centre de \\ Cabrils, Ctra. de Cabrils s/n, ES-08348 Cabrils (Barcelona), Spain
}

AdDitional IndeX words. Cucumis sativus, Cucurbitaceae, parthenogenesis, haploid, DHL, pure line, hybrid

\begin{abstract}
Homozygous doubled haploid lines (DHLs) from new cucumber (Cucumis sativus L.) accessions could be useful to accelerate breeding for resistant varieties. DHLs have been generated by in vitro rescue of in vivo induced parthenogenic embryos. The protocol developed involves the following: 1) induction of parthenogenic embryos by pollinating with pollen irradiated with a $\mathrm{Co}^{60} \gamma$-ray source at $500 \mathrm{~Gy} ; 2$ ) in vitro rescue of putative parthenogenic embryos identified by their morphology and localized using a dissecting scope or X-ray radiography; 3) discrimination of undesirable zygotic individuals from the homozygous plants using cucumber and melon SSR markers; 4) determination of ploidy level from homozygous plants by flow cytometry; 5) in vitro chromosome doubling of haploids; and 6) acclimation and selfing of selected lines. Codominant markers and flow cytometry confirmed the gametophytic origin of plants regenerated by parthenogenesis, since all homozygous lines were haploids. No spontaneous doubled haploid plants were rescued. Chromosome doubling of haploid plants was accomplished by an in vitro treatment with $500 \mu \mathrm{M}$ colchicine. Rescue of diploid or chimeric plants was shown by flow cytometry, prior to their acclimation and planting in the greenhouse. Selfing of colchicine-treated haploid plants allowed for the perpetuation by seed of homozygous lines. The high rate of seed set, $90 \%$ of the lines produced seed, facilitated the recovery of inbred lines. Despite some limiting factors, parthenogenesis is routinely used in a cucumber-breeding program to achieve complete homozygosity in one generation. Breeding for new commercial hybrid cultivars will be accelerated. DHLs are ideal resources for genomic analyses.
\end{abstract}

Production of haploids through androgenesis or parthenogenesis is frequently used in modern breeding programs of several vegetable (Dolcet-Sanjuan et al., 1997; Morales et al., 2002; Oliver et al., 2000) and ornamental species (Dolcet-Sanjuan et al., 2001). Chromosome doubling of haploids allows for the production of homozygous doubled haploid lines (DHLs), which, once perpetuated by seed, can be used in hybrid production. Breeding for resistance to diseases in new cucumber hybrid varieties can benefit from a reliable method to produce a high number of DHLs.

The effect of pollination with $\gamma$-irradiated pollen on cucumber ovule development was first reported by Truong-Andre (1988). After being developed for melon (Cucumis melo L.) by Sauton and Dumas de Vaulx (1987), the excision of 3-week-old parthenogenic embryos followed by in vitro rescue was applied to cucumber by Sauton (1989) and Niemirowicz-Szczytt and Dumas de Vaulx (1989). Detailed analysis of cucumber haploid plants, as well as evaluation of the genotype, pollen irradiation dose, and season effects on frequency of haploid embryo development, were first reported by Przyborowski and Niemirowicz-Szczytt (1994), Çaglar and Abak, (1996), and reviewed in Przyborowski (1996). Later, efforts were dedicated to improve the haploid production efficiency, measured as haploid plants regenerated per fruit, and the production of doubled haploid plants via chromosome doubling, in order to develop cultivars (Çaglar and Abak, 1997,

Received for publication 5 Nov. 2004. Accepted for publication 16 Jan. 2005 This work was supported in part by the Spanish seed company Semillas Fitó S.A., and the Spanish Ministry of Science and Technology (MCYT) under the research project "2FD1997-0325." We thank Dr. Jaume Comas, Serveis Científico-Tècnics, Universitat de Barcelona, for his help with the flow cytometry determinations. Use of trade names does not imply endorsement of the products named nor criticism of similar ones not named.

'To whom correspondence should be addressed (e-mail: ramon.dolcet@irta.es)
1999). These reports indicated that the number of haploid lines generated by in situ induced parthenogenesis ranged from 0.2 to 0.9 per 100 seeds. However, no rates were reported for the number of fertile DHLs perpetuated by seeds.

The application of gynogenesis (Dirks, 1996; Gémesné-Juhász et al., 1997) and androgenesis (Kumar et al., 2003), through in vitro ovary and anther culture, were described as alternative but not more efficient approaches to generate haploids in cucumber than parthenogenesis. These three reports measured the production of haploid plants but gave no details about the recovery of fertile DHLs, essential for the use of these techniques in breeding programs.

Herein, a protocol for the production of cucumber DHLs is described, which has proved to be valuable for the generation of short- and long-fruit-type commercial hybrids. The protocol is based on in situ induced parthenogenesis and in vitro embryo rescue. Optimization of the different steps, from parthenogenic embryo induction to perpetuation of DHLs by seed, is discussed. Flow cytometry and microsatellites are used to assess the ploidy level and the homozygosity of the generated lines.

\section{Materials and Methods}

Plant material and pollination with irRadiated pollen. Ten gynoecious cucumber $\mathrm{F}_{1}$ hybrids with long fruit (CS9701, CS9901 to CS9903, CS0001 to CS0004, CS0103 and CS0104) and two of short fruit (CS0101 and CS0102) were used as mother plants. A pure line, LP1, with thorns on fruits, stems, and leaves, as a dominant morphological character, was used as pollen donor. LP1 had a SSR pattern distinctive from the mother $F_{1}$ hybrids. All the plant material, gynoecious hybrids and the monoecious pure line LP1, were provided by Semillas Fitó S.A., and, since they are proprietary material, the pedigrees of these genotypes cannot be provided at this time. Collected male flowers, from 
LP1, were irradiated at 250 or $500 \mathrm{~Gy}$, with a $\mathrm{Co}^{60} \gamma$-ray source. Pistillate flowers of the $\mathrm{F}_{1}$ hybrids were bagged $1 \mathrm{~d}$ before the corolla opened, to avoid undesirable crosses. Next morning, while stigmas were receptive, pollination with irradiated LP1 pollen was performed and flowers were bagged again. Three to 5 weeks after pollination fruits were harvested and embryos cultured in vitro.

Detection of PUTATIVEly PARTHENOGENiC EMBRyos BY $\mathrm{X}$ RAY RADIOGRAPHY. Eighty-four fruits of four cucumber hybrids (CS0001 to 4) were opened under aseptic conditions, 3 to 5 weeks after pollination with $\gamma$-irradiated pollen, and 12,000 seeds were selected and displaced on a gel blotting paper. Seeds were dried for $1 \mathrm{~h}$, at $25^{\circ} \mathrm{C}$, in a flow hood chamber, and inserted in a sterile Omnitray (Nalge Europe Ltd., Hereford, U.K.) with lid. This dish was placed on a black and white Polapan 52 film (Polaroid Corp., Luton, U.K.) and introduced in a Faxitron model MX-20 cabinet (Faxitron X-ray Corp., Wheeling, Ill.). In preliminary trials, best results were obtained setting the voltage of the X-ray tube to 16 $\mathrm{kV}$, and the exposure time to $70 \mathrm{~s}$. Each radiography allowed for the imaging of $\approx 100$ to 150 seeds. Cucumber seeds from fruits harvested 3 weeks after self-pollination were used under the same conditions to determine the reliability of the X-ray radiography in detecting zygotic embryos.

IN VITRO RESCUE OF PUTATIVE PARTHENOGENIC EMBRYOS. Three to 5 weeks after pollination fruits were harvested, seeds extracted under sterile conditions, and in situ induced parthenogenic embryos were rescued in vitro by culture in E20H8 medium. Fruits were disinfected by spraying their surface with $96 \%$ (v/v) ethanol. Onethird of the fruit, the proximal part to the pedicel, was discarded since preliminary results indicated that it contained no embryos. Parthenogenic embryos were identified by their morphology, such as absence or nonsymmetric displacement of cotyledons or other abnormalities. The E20H8 medium was based on the E20 (Sauton and Dumas de Vaulx, 1987), supplemented with $7.9 \mathrm{~mm}$ $\mathrm{CaCl}_{2} \cdot 2 \mathrm{H}_{2} \mathrm{O}, 0.17 \mathrm{~mm} \mathrm{CoCl}_{2} \cdot 6 \mathrm{H}_{2} \mathrm{O}, 0.10 \mathrm{~mm}$ FeEDTA, $20 \mathrm{~g} \cdot \mathrm{L}^{-1}$ sucrose, and $8 \mathrm{~g} \cdot \mathrm{L}^{-1}$ Bacto agar (Difco Laboratories, Detroit). The $\mathrm{pH}$ was adjusted to 5.9 before autoclaving. During the first two subcultures this medium was supplemented with $0.06 \mu \mathrm{M}$ IAA and $15 \mu \mathrm{M}$ silver thiosulfate (STS), to promote root growth and overcome vitrification, respectively.

Embryos were extracted from seeds and plated in petri dishes (6 cm diameter) with $10 \mathrm{~mL}$ of E20H8 medium. Cultures were incubated at $28{ }^{\circ} \mathrm{C}$ with a $16-\mathrm{h}$ photoperiod $\left(50 \mu \mathrm{mol} \cdot \mathrm{m}^{-2} \cdot \mathrm{s}^{-1}\right)$. A maximum of four subcultures to fresh medium were done every 2 weeks. Developed plantlets were transferred to tubes, and later on to flasks, with E20H8 medium, following micropropagation by axillary branching. During micropropagation, cultures were incubated at $28{ }^{\circ} \mathrm{C}$ with a 16 -h photoperiod $\left(70 \mu \mathrm{mol} \cdot \mathrm{m}^{-2} \cdot \mathrm{s}^{-1}\right)$. Plantlets with a good root system and four to six normal leaves were acclimated in Jiffy-7 peat plugs (Clause Tézier SA, Portesles-Valence, France).

Homozygosity AND Ploidy Determinations. The origin of lines, obtained by in vitro embryo rescue and micropropagation, was determined by the microsatellite (SSRs) patterns complemented with the ploidy level, determined by flow cytometry. Lines that were heretozygous for any of the SSRs used (CMGA165, CSAT425, CMAG59, and CMSSR1), therefore originated from zygotic embryos, were eliminated. Zygotic embryos could originate from viable pollen of LP1 unaffected by $\gamma$-ray irradiation or from uncontrolled pollinations. Lines homozygous for all SSRs, presumably originated from parthenogenic embryos, were maintained in vitro and their ploidy level was determined. Flow cytometry was used to determine the DNA content of each line, during in vitro micropropagation and after in vitro colchicine treatment. Young leaves from actively growing plants were finely chopped and macerated for 5 min into $1 \mathrm{~mL} \mathrm{LB01} \mathrm{lysis} \mathrm{buffer}$ (Dolcet-Sanjuan et al., 1997), with 2\% (v/v) Triton X-100 to release intact nuclei. The supernatant was filtered through a $56-\mu \mathrm{m}$ nylon mesh. The nuclei were labeled with propidium iodide, and red fluorescence was analyzed using a 675-nm band-pass filter. Results were presented in a histogram expressing the distribution of nuclei according to the red fluorescence intensity, which is proportional to the DNA content.

SSR ANALYSIS. Four SSR markers were used for the homozygosity test of the haploid lines: CMGA165 and CSAT425 (Danin-Poleg et al., 2001), CMAG59 (Katzir et al., 1996), and CMSSR1 (Garcia-Mas, unpublished). CMGA165, CMAG59, and CMSSR1 are melon SSRs, and CSAT425 is a cucumber SSR. PCR reactions were performed in a final volume of $15 \mu \mathrm{L}$ with $1 \times$ Taq buffer [20 mm $\left(\mathrm{NH}_{4}\right) \mathrm{SO}_{4}, 75 \mathrm{~mm}$ Tris- $\mathrm{HCl} \mathrm{pH} \mathrm{8.8,0.01 \%}$ (v/v) Tween 20], 2 mм $\mathrm{MgCl}_{2}, 166 \mu \mathrm{m}$ dNTPs, 2 pmol of each primer (one labelled with the fluorochrome IRD-800), 1 unit of Taq DNA polymerase (Applied Biosystems, Foster City, Calif.), and $60 \mathrm{ng}$ of DNA. The cycling conditions were as follows: an initial cycle at $94{ }^{\circ} \mathrm{C}$ for 1 min followed by 35 cycles at $94{ }^{\circ} \mathrm{C}$, $30 \mathrm{~s} ; 40-60{ }^{\circ} \mathrm{C}, 30 \mathrm{~s} ; 72{ }^{\circ} \mathrm{C}, 1 \mathrm{~min}$; and a final cycle at $72{ }^{\circ} \mathrm{C}$ for 5 min. SSR fragments were separated in a LI-COR IR² (LICOR, Lincoln, Nebr.) automatic sequencer. Five microliters of loading buffer [95\% (v/v) formamide, 20 mм EDTA, 0.05\% $(\mathrm{w} / \mathrm{v})$ bromophenol blue, $0.05 \%(\mathrm{w} / \mathrm{v})$ xylene cyanol] were added to the PCR mix, samples were denatured at $100{ }^{\circ} \mathrm{C}$ for $5 \mathrm{~min}$ and $0.8 \mu \mathrm{L}$ were loaded on to a LI-COR IR ${ }^{2}$ sequencer using $25-\mathrm{cm}$ plates with $6 \%(\mathrm{w} / \mathrm{v})$ acrylamide in $1 \times \mathrm{TBE}$ and $7.5 \mathrm{~m}$ urea. Electrophoresis was performed at $1500 \mathrm{~V}, 35 \mathrm{~mA}$, and $31 \mathrm{~W}$ at $50{ }^{\circ} \mathrm{C}$ until the PCR products were visible. The molecular weight of each microsatellite band was estimated by comparing its migration with the IRD-labelled STR molecular size marker (LI-COR).

Chromosome doubling of Haploid Plants. As shown by flow cytometry, most of the rescued lines, homozygous for all SSRs, were haploid. Micropropagation of haploid lines was required before their chromosome number was doubled in vitro with a colchicine treatment. This was performed on 100 to 200 cuttings, with one or two axillary buds each, per line. Explants were either cultured in petri dishes $(10 \mathrm{~cm}$ diameter) or polystyrene RA40 Microboxes (Combiness, Gent, Belgium) with E20H8 medium supplemented with $500 \mu \mathrm{M}$ colchicine, dissolved in dimethyl sulfoxide (DMSO). Forty-eight hours later, explants were transferred to colchicine-free E20H8 medium. Four to 8 weeks later, new shoots grew up from some explants, out of most of the parthenogenic lines. Twenty shoots per line were rescued and individually micropropagated in E20H8 medium. Doubled haploid lines, confirmed by flow cytometry, were maintained in vitro until they were acclimated and transferred to the greenhouse for self-pollination.

SElf-POllination AND PERPETUATION OF DOUBLED HAPLOID LINES. At least 20 plants from each doubled haploid line were acclimated, hardened, and transferred to the greenhouse for self-pollination. Induction of staminate flowers on gynoecious cucumber lines was achieved by spraying with STS. After a first selfing, lines with a sufficient number of seeds were eliminated from the in vitro stock, and a second self-pollination was performed on the remaining lines. A minimum of 50 seeds was considered necessary to perpetuate a doubled haploid line. 


\section{Results and Discussion}

Plant material. Inbred lines and hybrids were the source of parthenogenic embryos in most of the previous reports (Çaglar and Abak, 1996, 1999; Niemirowicz-Szczytt and Dumas de Vaulx, 1989; Przyborowski, 1996; Przyborowski and NiemirowiczSzczytt, 1994). Herein, and for the first time, in situ induction of haploid parthenogenic embryos through pollination with $\gamma$-irradiated pollen has been reported on parthenocarpic, gynoecious cucumber $\mathrm{F}_{1}$ hybrids of short and long fruits.

During the determination of the optimal irradiation dose (Fig. $1)$, the genotype had no significant effect $(P=0.074)$. With a more extensive number of genotypes, the maternal plant was the main factor affecting the rate of parthenogenic embryos produced (Table 1). Similar results were reported previously, with values ranging from 0.3 to 1.7 embryos per 100 seeds (Przyborowski and Niemirowicz-Szczytt, 1994; Przyborowski, 1996) or as high as 5.3 for one hybrid (Çaglar and Abak, 1996, 1999). These values, apparently lower (Table 1), are not comparable to the latter since they have been obtained from different cucumber types and correspond to the rescued parthenogenic embryos and not

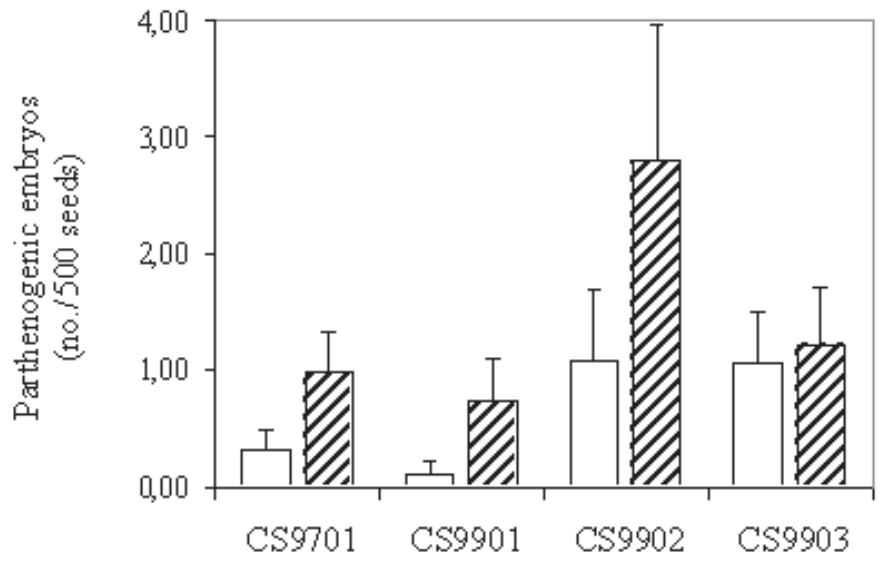

F1 hybrid

Fig. 1. Effect of $\mathrm{Co}^{60} \gamma$-irradiation dose, at $250(\square)$ and $500 \mathrm{~Gy}(\mathbb{Z})$, of LP1 pollen on the number of cucumber parthenogenic embryos per 500 seeds. Average of 30 fruits per hybrid. Vertical bars $=$ SE.

to the total number of embryos observed, which is dependent on the morphological criteria used to determine the embryos origin. The reported average number of embryos developed to plants per 100 seeds was 0.3 in Troung-Andre (1988), 0.9 in Çaglar and Abak (1996), and 0.2 to 0.8 in Przyborowski (1996), which are close to the results of rescued parthenogenic embryos shown in Table 1.

Pollen irRadiation dose. The basis to select between the two $\mathrm{Co}^{60} \gamma$-irradiation doses (250 or $500 \mathrm{~Gy}$ ) was to enhance the formation of parthenogenic embryos and to minimize the formation of zygotic embryos. Without significant interaction $(P$ $=0.635$ ) between genotype and doses of irradiation, a significant increase $(P=0.043)$ of the number of parthenogenic embryos produced was observed with $500 \mathrm{~Gy}$ (Fig. 1), with no significant difference between the genotypes $(P=0.074)$. At both irradiation doses the generative nuclei of pollen were inactivated, avoiding the formation of zygotic embryos. Other reports had focused on lowering the dose of 400 or $600 \mathrm{~Gy}$, first reported by TroungAndre (1988), to improve the rate of parthenogenic embryo induction (Çaglar and Abak, 1996, 1999; Przyborowski, 1996; Przyborowski and Niemirowicz-Szczytt, 1994). Although they all reported a beneficial effect on the number of embryos, from lowering the dose of irradiation to 200 and $300 \mathrm{~Gy}$, there was no statistical difference observed. In addition, although the number of putative parthenogenic embryos increased after lowering the irradiation dose, the number of embryos developing into plants was not enhanced (Przyborowski, 1996). Therefore, the 500-Gy dose was chosen to irradiate pollen of the cucumber line LP1 as inducer of parthenogenic embryos.

Season to induce parthenogenesis. As reported by Przyborowski and Niemirowicz-Szczytt (1994), Przyborowski(1996), and Çaglar and Abak $(1996,1999)$, summer was the optimal season to induce parthenogenesis through pollination with $\gamma$-irradiated pollen, because it is the best season to induce parthenocarpy in the $\mathrm{F}_{1}$ hybrids. In our conditions, parthenogenesis was inducible during the months of May through July, with no differences within this period (data not shown).

DETECTION OF PUTATIVELY PARTHENOGENIC EMBRYOS BY X-RAY RADIOGRAPHY. The effectiveness of X-ray radiography to detect and identify seeds containing immature cucumber embryos was $32 \%$ (six embryos found by X-rays out of 19 embryos found under a dissecting scope). This efficiency was lower than that indicated Table 1. Production of cucumber (Cucumis sativus L.) doubled haploid lines (DHLs) originated from in vitro rescue of in situ induced parthenogenic embryos.

\begin{tabular}{|c|c|c|c|c|c|c|c|c|}
\hline \multirow[b]{2}{*}{ Hybrid } & \multirow{2}{*}{$\begin{array}{c}\text { Fruits } \\
\text { (no.) }\end{array}$} & \multirow{2}{*}{$\begin{array}{c}\text { Seeds } \\
\text { (no.) }\end{array}$} & \multirow{2}{*}{$\begin{array}{c}\text { Parthenogenic } \\
\text { embryos } \\
\text { (no.) }\end{array}$} & \multicolumn{2}{|c|}{$\begin{array}{c}\text { Rescued } \\
\text { parthenogenic embryos }\end{array}$} & \multicolumn{2}{|c|}{$\begin{array}{c}\text { DHLs with more than } \\
50 \text { seeds (no.) }\end{array}$} & \multirow{2}{*}{$\begin{array}{c}\text { DHLs } \\
\text { (no./500 seeds) }\end{array}$} \\
\hline & & & & (no.) & (no./500 seeds) & 1st selfing & 2nd selfing & \\
\hline CS9701 & 81 & 21741 & 18 & 13 & 0,3 & 11 & 11 & 0.3 \\
\hline CS9901 & 61 & 19865 & 10 & 9 & 0,2 & 5 & 9 & 0.2 \\
\hline CS9902 & 43 & 6563 & 17 & 16 & 1,2 & 12 & 15 & 1.1 \\
\hline CS9903 & 86 & 18265 & 24 & 21 & 0,6 & 18 & 21 & 0.6 \\
\hline CS0001 & 77 & 9146 & 15 & 10 & 0,5 & 8 & 10 & 0.5 \\
\hline $\mathrm{CS} 0002$ & 37 & 4933 & 22 & 17 & 1,7 & 12 & 16 & 1.6 \\
\hline $\mathrm{CS} 0003$ & 108 & 28402 & 15 & 14 & 0,2 & 11 & 14 & 0.2 \\
\hline CS0004 & 94 & 26575 & 18 & 16 & 0,3 & 13 & 17 & 0.3 \\
\hline CS0101 & 62 & 18979 & 10 & 7 & 0,2 & 6 & 7 & 0.2 \\
\hline CS0102 & 77 & 26534 & 22 & 21 & 0,4 & 15 & 15 & 0.3 \\
\hline CS0103 & 49 & 11227 & 11 & 8 & 0,4 & 4 & 4 & 0.2 \\
\hline CS0104 & 73 & 19797 & 10 & 8 & 0,2 & 5 & 5 & 0.1 \\
\hline Total & 848 & 212027 & 192 & 160 & 0,4 & 120 & 144 & 0.3 \\
\hline
\end{tabular}
total of 17 seeds were selected with $\mathrm{X}$-ray radiography as containing embryos (Fig. 2). However, after visualization under the dissecting scope, only six were shown to have embryos, the rest were enlargement of the integuments. In addition, 13 embryos were found by dissection in those seeds not selected by X-ray radiography imaging. Moreover, the viability of the embryos after the required drying and manipulation of seeds to perform the X-ray radiography was reduced to $40 \%$, while that after direct dissection was more than twice this value (see next section). In consequence, since the method was not effective in cucumber, seeds were selected 
and opened under a dissecting scope. Some immature cucumber seed covers are translucent and in other cases the embryos grow out of the seed covers (Fig. 3A), allowing for a first selection of the seeds containing embryos.

IN VITRO RESCUE OF PUTATIVELY PARTHENOGENIC EMBRYOS. In vitro rescue of putatively parthenogenic embryos (Fig. 3) in E20H8 medium, supplemented with IAA and STS, allowed for an average embryo rescue of $83 \%$ of the embryos into plants (Table 1). Niemirowicz-Szczytt et al. (2000) found difficulties in conserving in vitro a collection of haploid cucumber plants. The maintenance by micropropagation of haploid lines or doubled haploids, after colchicine treatment, presented no difficulties in the E2OH8 medium.

Homozygosity AND Ploidy Determinations. Ploidy level determinations by flow cytometry (Fig. 4), of lines derived from putative parthenogenic embryos, showed that $62 \%$ of them were haploid plants (Table 2), with $<30 \%$ of their nuclei being diploid (Fig. 4A). In addition, although $38 \%$ of the lines were chimeric (Table 2), with haploid cells and a predominant number of diploid nuclei (Fig. 4B), no complete diploid lines were observed (Table 2 ). This is in concordance with the spontaneous chromosome doubling observed in some root meristems after micropropagation of haploid lines (Niemirowicz-Szczytt and Dumas de Vaulx, 1989; Przyborowski, 1996; Przyborowski and Niemirowicz-Szczytt, 1994). The use of cucumber and melon SSR markers was useful to discriminate the existence of undesirable zygotic individuals from the homozygous plants (Fig. 5). Panels A, B, and C show that none of the lines inherited the LP1 allele, discarding the possibility of a functional LP1 pollen. SSR patterns in panels D, $\mathrm{E}$, and $\mathrm{F}$ show that lines inherited either one of the alleles present in the respective hybrids. A zygotic individual is identified in panel E. This has two alleles: one coming from the pollen donor LP1 and another from the hybrid CS9902. Codominant
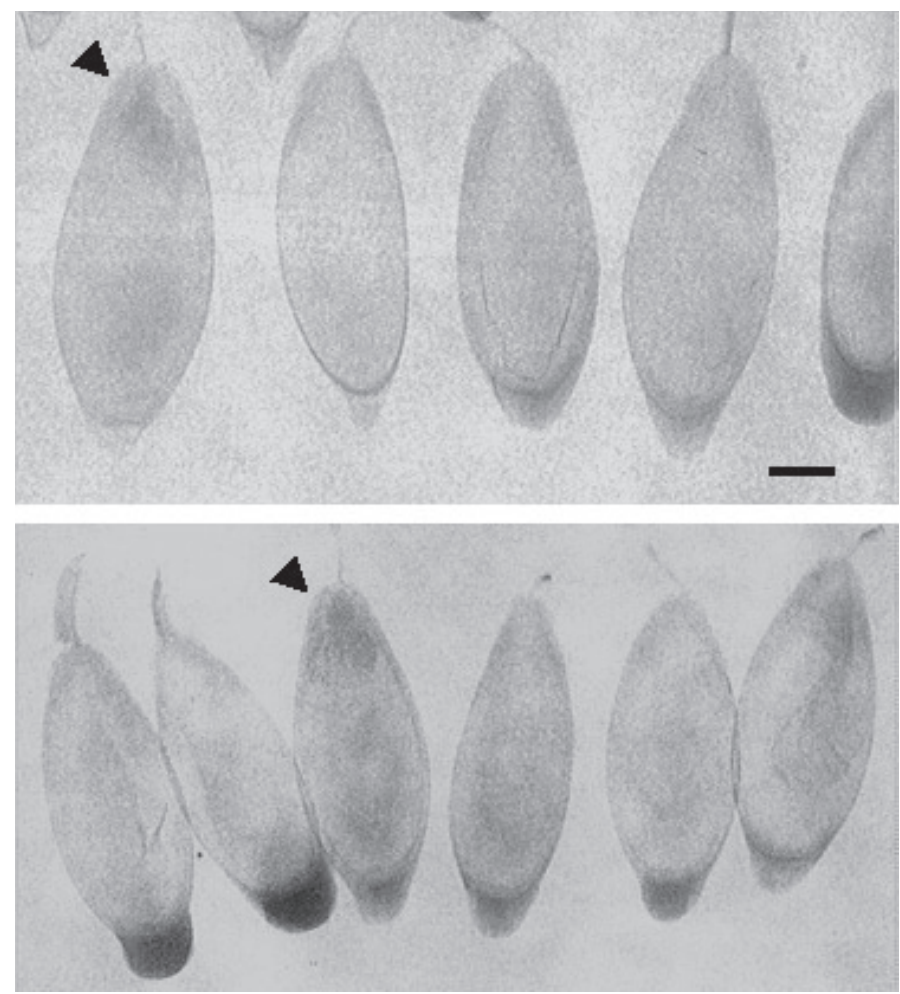

Fig. 2. Sample X-radiography of cucumber seeds 3 weeks after pollination with $\gamma$-irradiated pollen, showing the presence (arrows) of parthenogenic embryos $($ bar $=2 \mathrm{~mm})$.
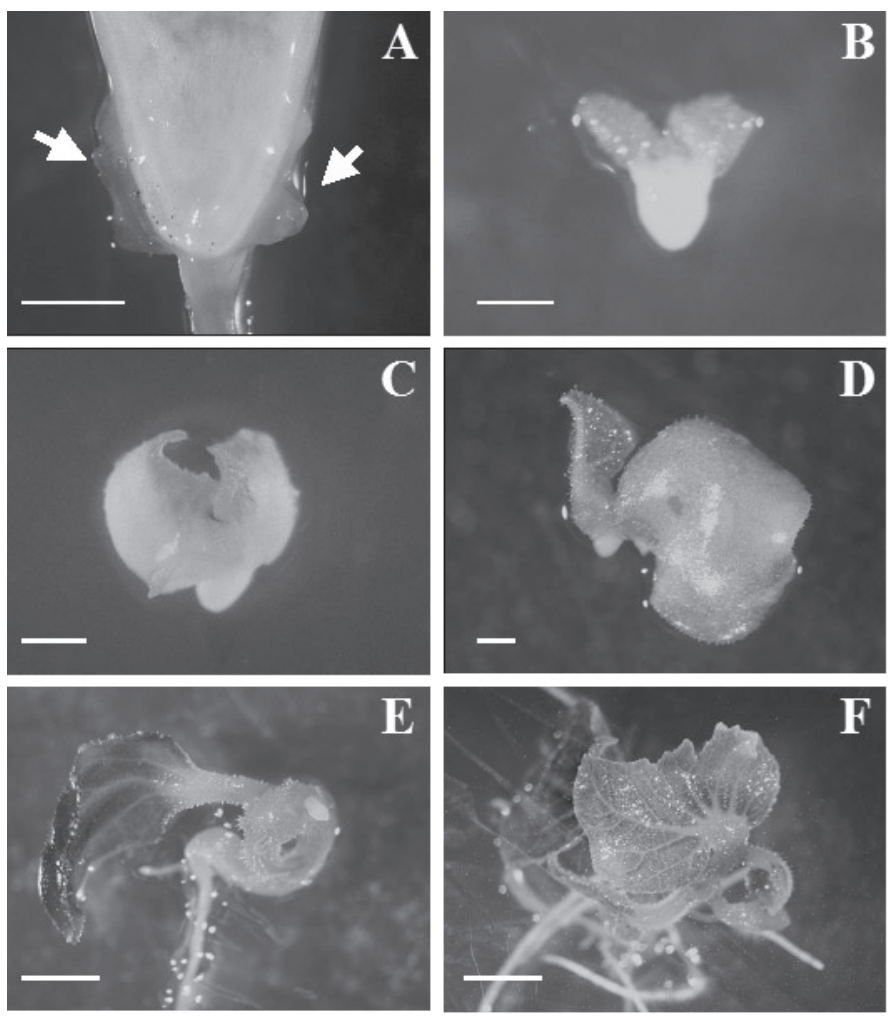

Fig. 3. In vitro rescue of cucumber parthenogenic embryos. Embryo emerging out of the seed cover (arrows) 3 weeks after pollination with $\gamma$-irradiated pollen $(\mathbf{A} ;$ bar $=1.5 \mathrm{~mm})$. Asymmetric parthenogenic embryos excised out of seeds $(\mathbf{B}$ and $\mathbf{C}$; bar $=1 \mathrm{~mm})$, cultured in vitro for 1 week $(\mathbf{D}$; bar $=1 \mathrm{~mm})$ or 3 weeks (E and $\mathbf{F}$; bar $=5 \mathrm{~mm}$ ).

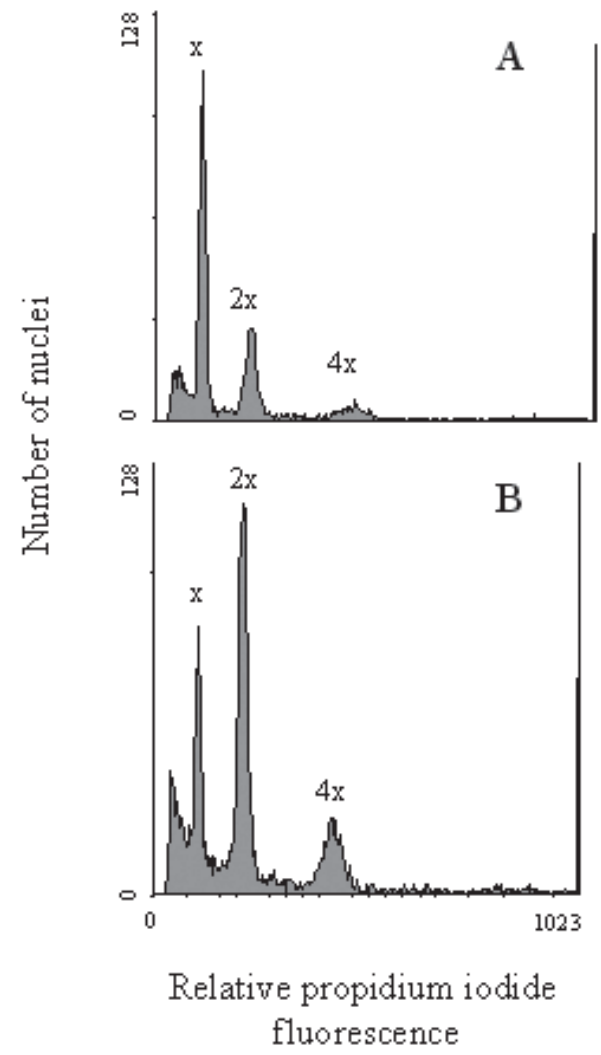

Fig. 4. Sample flow cytometry histograms of a chimeric haploid and doubled haploid cucumber line, before $(\mathbf{A})$ and after $(\mathbf{B})$ in vitro colchicine treatment. 
Table 2. Ploidy level of cucumber (Cucumis sativus L.) parthenogenic lines before and after in vitro colchicine treatment.

\begin{tabular}{|c|c|c|c|c|c|c|c|}
\hline \multirow[b]{3}{*}{ Hybrid } & \multirow{3}{*}{$\begin{array}{c}\text { Lines } \\
\text { (no.) }\end{array}$} & \multicolumn{6}{|c|}{ Ploidy level } \\
\hline & & \multicolumn{2}{|c|}{$\mathrm{x}$} & \multicolumn{2}{|c|}{$x+2 x$} & \multicolumn{2}{|c|}{$2 \mathrm{x}$} \\
\hline & & no. & $\%$ & no. & $\%$ & no. & $\%$ \\
\hline \multicolumn{8}{|c|}{ Before colchicine treatment } \\
\hline$\overline{C S 9701}$ & 14 & 8 & 57 & 6 & 43 & 0 & 0 \\
\hline CS9901 & 9 & 6 & 67 & 3 & 33 & 0 & 0 \\
\hline CS9902 & 17 & 7 & 41 & 10 & 59 & 0 & 0 \\
\hline CS9903 & 21 & 17 & 81 & 4 & 19 & 0 & 0 \\
\hline Total & 61 & 38 & 62 & 23 & 38 & 0 & 0 \\
\hline \multicolumn{8}{|c|}{ After colchicine treatment } \\
\hline$\overline{\text { CS9701 }}$ & 12 & 2 & 17 & 7 & 58 & 3 & 25 \\
\hline CS9901 & 9 & 1 & 11 & 5 & 56 & 3 & 33 \\
\hline CS9902 & 15 & 3 & 20 & 9 & 60 & 3 & 20 \\
\hline CS9903 & 20 & 2 & 10 & 10 & 50 & 8 & 40 \\
\hline Total & 56 & 8 & 14 & 31 & 55 & 17 & 30 \\
\hline
\end{tabular}

markers and flow cytometry confirmed the gametophytic origin of plants regenerated by parthenogenesis, since all homozygous lines were complete haploids or had some haploid cells in the aerial part of the plant. These results validated the effectiveness of the morphological characters used to select the putatively parthenogenic embryos (Fig. 3).

Chromosome doubling of haploid Plants. Chromosome doubling of haploid plants was accomplished by an in vitro treatment with $500 \mu \mathrm{m}$ colchicine. In vitro chromosome doubling of haploids allowed for the recovery of viable plants from all the lines. Survival of explants to the colchicine treatment depended on the haploid line, with a normal distribution among the 143 haploid lines treated (Fig. 6). From most of the lines, 20\% to $60 \%$ of the treated explants produced new shoots. Such recovered shoots had broader and thicker leaves that indicated a possible change in their ploidy level (Fig. 7). After colchicine treatment, $30 \%$ of the rescued plants became complete diploids, $55 \%$ were

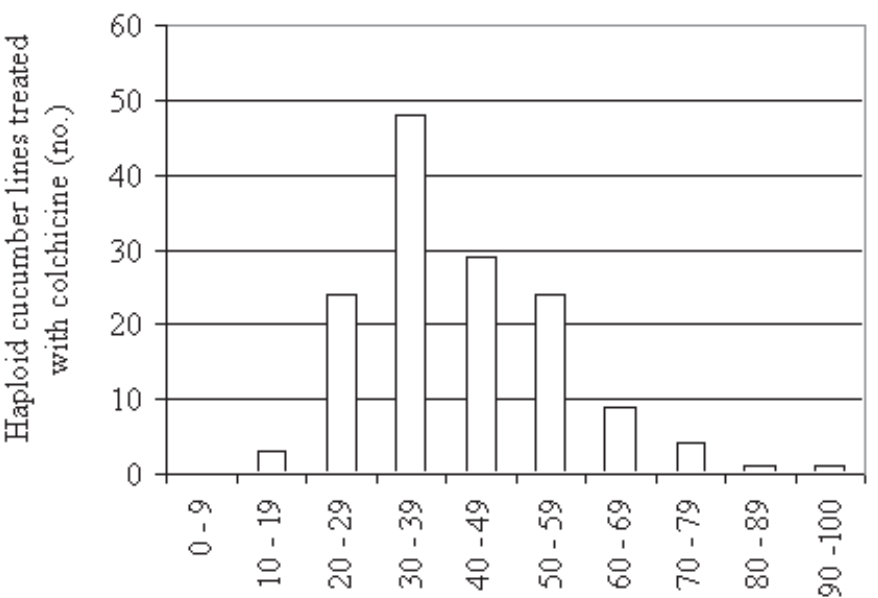

Surviving explants forming new shoots (\%)

Fig. 6. Distribution of explant survival after in vitro colchicine treatment of haploid cucumber lines.

chimeric plants with haploid and diploid cells (Fig. 4B), and only a $14 \%$ remained complete haploids (Table 2). The percentage $(85 \%)$ of doubled haploid lines obtained with the methodology described here was higher than the $60 \%$ obtained by immersion in a colchicine solution (Çaglar and Abak, 1997).

Self-POLLINATION AND PERPETUATION OF DOUBLED HAPLOID LINES. Homozygous DHLs were perpetuated by seed after selfpollination of the doubled haploid lines, derived from in vitro colchicine-treated haploid cultures. Acclimation and selfing of lines allowed for the perpetuation by seed of $75 \%$ of the lines after a first selfing, and $90 \%$ after a second self-pollination. Seeds were harvested from 144 out of 160 parthenogenic doubled haploid lines (Table 1). The high rate of seed production facilitated the recovery of inbred lines (Fig. 8).

In conclusion, the gametophytic origin of lines regenerated from putative parthenogenic embryos has been demonstrated by
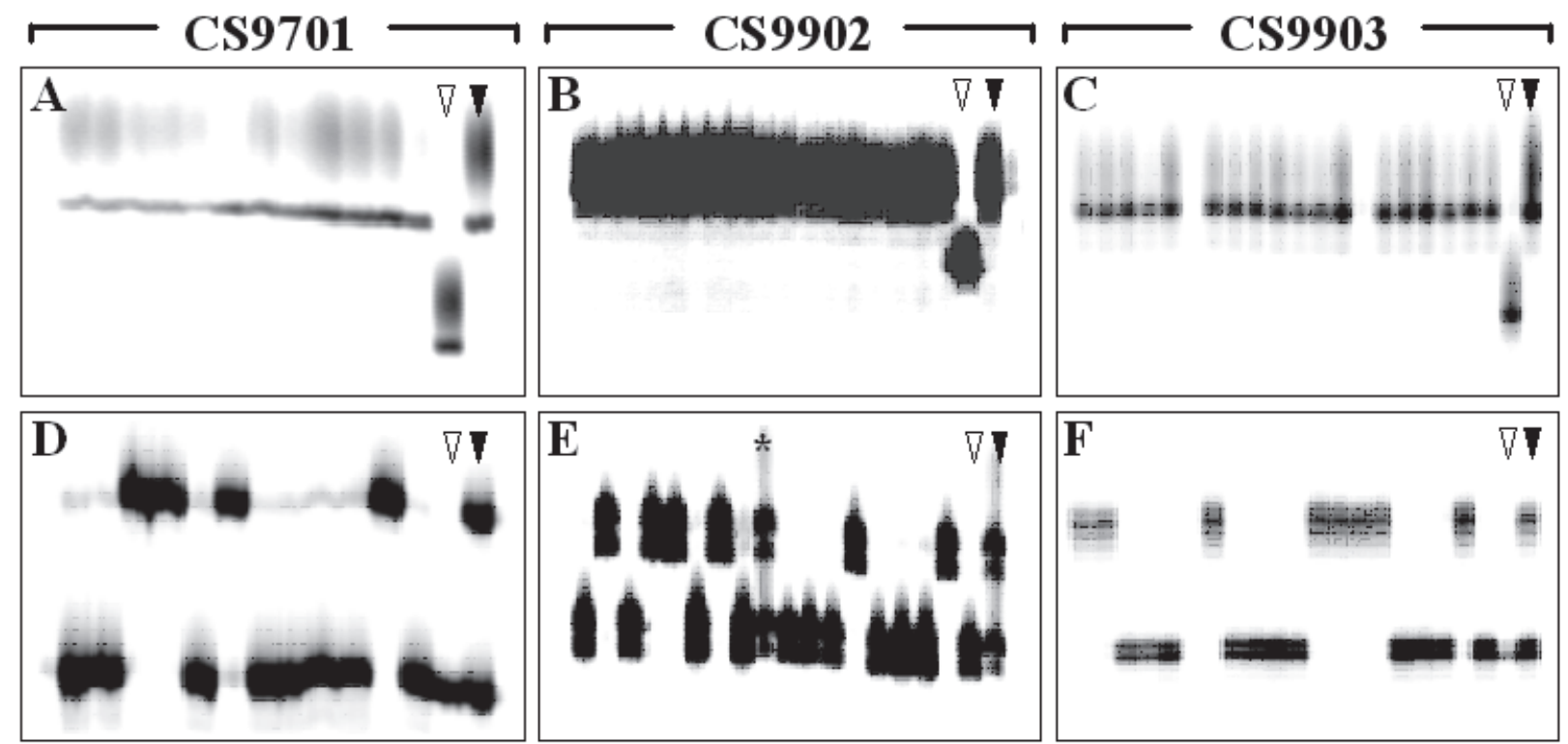

Fig. 5. Microsatellites CSAT425 (A, B, and C), CMAG59 (D and E), and CMSSR1 (F) profiles from CS9701, CS9902, and CS9903 cucumber Fi hybrids ( $\mathbf{\nabla}$ ), cucumber pollen donor line LP1 $(\nabla)$, a diploid cucumber zygotic line $(*)$ from CS9902 crossed with LP1, and putative parthenogenic lines (remaining lanes). 


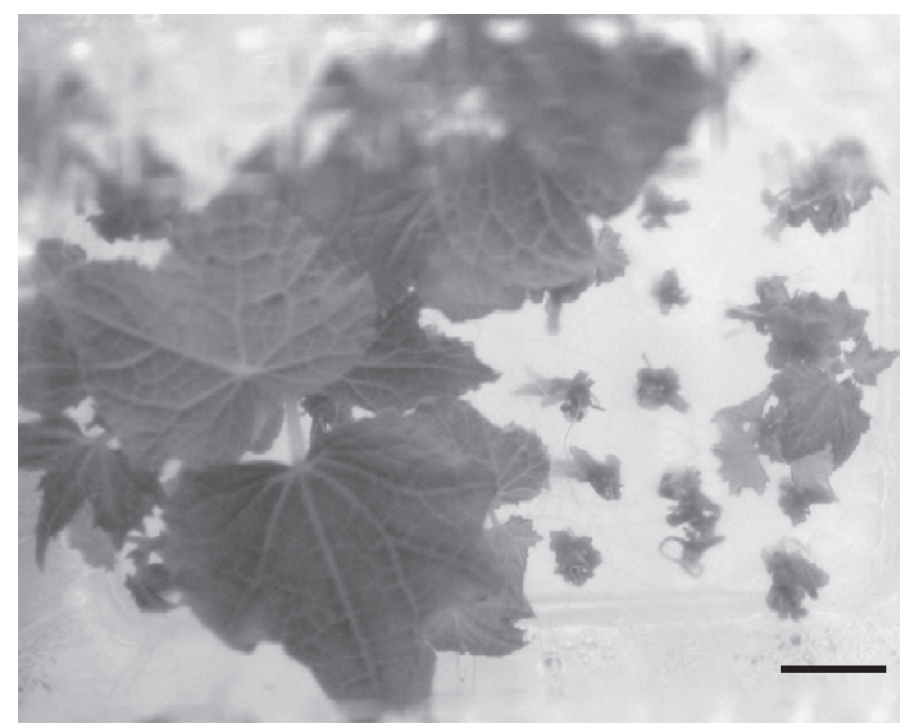

Fig. 7. New cucumber shoots growing on explants treated with colchicine (bar $=1 \mathrm{~cm})$.

flow cytometry and SSRs markers. No spontaneous chromosome doubling was observed among the in vitro rescued lines. In vitro colchicine treatment induced diploid or chimeric plants, with diploid and haploid cells. However, their level of fertility was high enough to perpetuate by seed most of the DHLs.

Despite some limiting factors in the rates of DHL production, parthenogenesis is routinely used in cucumber-breeding programs to achieve complete homozygosity in one generation, and accelerate breeding for new commercial varieties. With this protocol, sufficient number of cucumber DHLs can be generated to be selected and incorporated in a breeding program for new resistant varieties, or to be used in hybrid production. So far, DHLs have been selected and used as parental lines for the production of new commercial hybrids.

\section{Literature Cited}

Çaglar, G. and K. Abak. 1996. Efficiency of haploid production in cucumber. Cucurbit Genet. Coop. Rpt. 19:36-37.

Çaglar, G. and K. Abak. 1997. In vitro colchicine application of haploid cucumber plants. Cucurbit Genet. Coop. Rpt. 20:21-23.

Çaglar, G. and K. Abak. 1999. Progress in the production of haploid embryos, plants and double haploids in cucumber (C. sativus L.) by gamma irradiated pollen, in Turkey. Acta Hort. 492:317-322.

Danin-Poleg, Y., N. Reis, G. Tzuri, and N. Katzir. 2001. Development and characterisation of microsatellite markers in Cucumis. Theor. Appl. Genet. 102:61-72.

Dirks, R. 1996. Method for the production of double-haploid cucumbers. U.S. Patent 5,492,827. Assignee Nunhems Zaden BV, Netherlands. U.S. Patent and Trademark Office, Washington, D.C.

Dolcet-Sanjuan, R., E. Claveria, and A. Huerta. 1997. Androgenesis in Capsicum annuum L. - Effects of carbohydrate and $\mathrm{CO}_{2}$ enrichment. J. Amer. Soc. Hort. Sci. 122:468-475.

Dolcet-Sanjuan, R., E. Clavería, M. Llauradó, A. Ortigosa, and P. Arús. 2001. Carnation (Dianthus caryophyllus L.) dihaploid lines resistant to Fusarium oxysporum f. sp. dianthi. Acta Hort. 560:141-144.

Gémesné-Juhász, A., G. Venczel, and P. Balogh. 1997. Haploid plant induction in zucchini (Cucurbita pepo L. convar. giromontiina Duch) and in cucumber (Cucumis sativus L.) lines through in vitro gynogenesis. Acta Hort. 447:623-624.
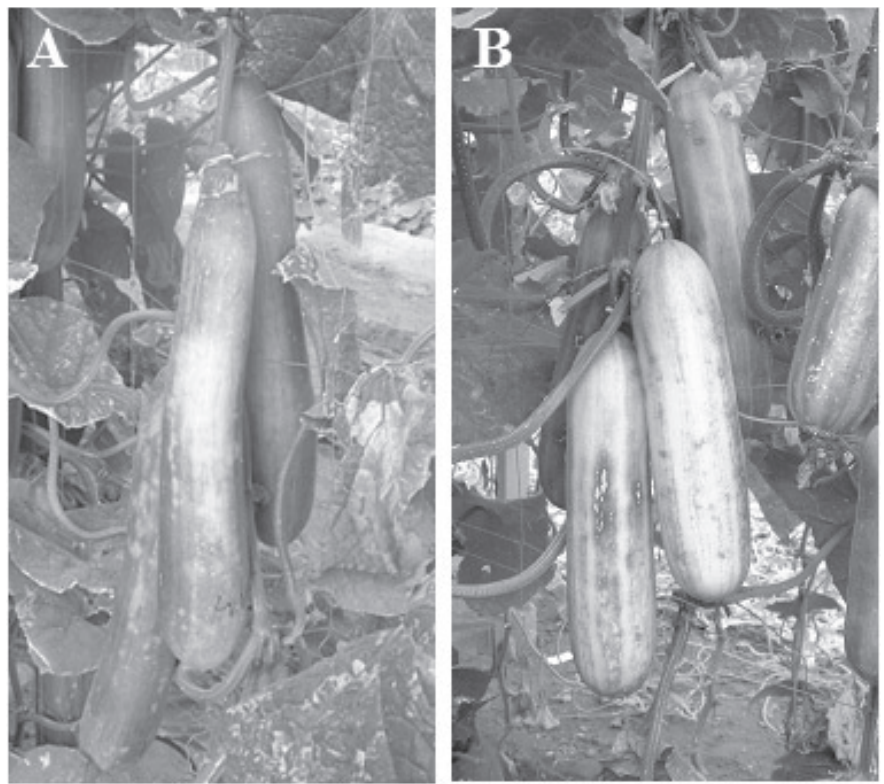

Fig. 8. Fruits with seed on self-pollinated cucumber doubled haploid lines of long (A) and short (B) fruit type.

Katzir, N., Y. Danin-Poleg, G. Tzuri, A. Karchi, U. Lavi, and P.B. Cregan. 1996. Length polymorphisms and homologies of microsatellites in several Cucurbitaceae species. Theoretical Appl. Genet. 93:1282-1290.

Kumar, H.G.A., H.N. Murthy, and K.Y. Paek. 2003. Embryogenesis and plant regeneration from anther cultures of Cucumis sativus L. Scientia Hort. 98:213-222.

Morales, M., M. Luís-Arteaga, J.M. Álvarez, R. Dolcet-Sanjuan, A. Monfort, P. Arús, and J. Garcia-Mas. 2002. Marker saturation of the region flanking the gene $N S V$ conferring resistance to the melon necrotic spot carmovirus (MNSV) in melon. J. Amer. Soc. Hort. Sci. 127:540-544.

Niemirowicz-Szczytt, K. and R. Dumas de Vaulx. 1989. Preliminary data on haploid cucumber (Cucumis sativus L.) induction. Cucurbit Genet. Coop. Rpt. 12:24-25.

Niemirowicz-Szczytt, K., N.M. Faris, M. Rucinska, and V. Nikolova. 2000. Conservation and storage of a haploid cucumber (Cucumis sativus L.) collection under in vitro conditions. Plant Cell Rpt. 19:311-314.

Oliver, M., J. Garcia-Mas, M. Morales, R. Dolcet-Sanjuan, M.C. de Vicente, H. Gómez, H. van Leeuwen, A. Monfort, P. Puigdomènech, and P. Arús. 2000. The Spanish melon genome project: Construction of a saturated genetic map. Acta Hort. 510:375-378.

Przyborowski, J.A. 1996. Haploidy in cucumber (Cucumis sativus L.), p. 91-98. In: S.M. Jain, S.K. Sopory, and R.E. Veilleux (eds.). In vitro haploid production in higher plants. Kluwer, Dordrecht, The Netherlands.

Przyborowski, J. and K. Niemirowicz-Szczytt. 1994. Main factors affecting cucumber (Cucumis sativus L.) haploid embryo development and haploid plant characteristics. Plant Breeding 112:70-75.

Sauton, A. 1989. Haploid gynogenesis in Cucumis sativus induced by irradiated pollen. Cucurbit Genet. Coop. Rpt. 12:22-23.

Sauton, A. and Dumas de Vaulx R. 1987. Induction of gynogenetic haploid plants in muskmelon (Cucumis melo L.) by use of irradiated pollen. Agronomie 7:141-148.

Sauton, A., C. Olivier, and A. Chavagnat. 1989. Use of soft X-ray technique to detect haploid embryos in immature seeds of melon. Acta Hort. 353:131-135.

Truong-Andre, I. 1988. In vitro haploid plants derived from pollination by irradiated pollen on cucumber. Proc. Eucarpia Mtg. on Cucurbitaceae, Avignon-Montfavet, France 88:143-144. 